\title{
Role of Cytoreductive Radical Prostatectomy in the Treatment of Metastatic Prostate Cancer
}

\author{
Luck Hee Sung1, Hyeong Dong Yuk ${ }^{2}$
}

\author{
${ }^{1}$ Department of Urology, Inje University Sanggye Paik Hospital, Seoul, Korea \\ ${ }^{2}$ Department of Urology, Seoul National University Hospital, Seoul, Korea
}

\begin{abstract}
There is controversy regarding the survival benefits of eliminating primary tumors via cytoreductive radical prostatectomy (CRP) in patients with metastatic prostate cancer (mPCa). The purpose of this article is to review the theoretical background of and rationale for CRP, and the current knowledge base. The Scopus and PubMed databases were searched for studies investigating CRP published between January 2000 and October 2019. The retrieved articles were nonsystematically reviewed. Based on preclinical data, retrospective patient case studies, retrospective population-based studies, and prospective studies, CRP has been reported to afford benefits for the treatment and prevention of local symptoms through the removal of primary tumors, and the management of neo-metastatic disease and overall survival. However, despite the results from these studies, the current review mostly addresses small case studies and uncontrolled population-based studies with weak evidence. Based on this weak evidence, therefore, clinical use has not yet been recommended. Further research investigating the role and timing of CRP in patients with $\mathrm{mPCa}$ is needed, in addition to studies screening the most suitable populations for CRP. (Korean J Urol Oncol 2020;18:161-169)
\end{abstract}

Key Words: Cytoreductive radical prostatectomy - Local treatment - Metastatic prostate cancer - Prostate cancer Radical prostatectomy

\section{INTRODUCTION}

Most prostate cancers are considered to be less aggressive in terms of malignancy and have a relatively good prognosis compared with other carcinomas; however, metastatic prostate cancer (mPCa) has a different prognosis.1 Five-year survival rates are close to $100 \%$ for patients with local prostate cancer, but $<30 \%$ for those with $\mathrm{mPCa}^{1}{ }^{1}$ These metastatic prostate cancers account for approximately $4 \%$ of ini-

Received November 21, 2019, Revised April 24, 2020

Accepted May 11, 2020

Corresponding Author: Hyeong Dong Yuk

Department of Urology, Seoul National University Hospital, 101

Daehak-ro, Jongno-gu, Seoul 03080, Korea

E-mail: hinayuk@naver.com

Tel: +82-2-2072-2427, Fax: +82-2-742-4665

ORCID: https://orcid.org/0000-0002-5874-9167 tially diagnosed prostate cancers, and $33 \%$ of local prostate cancers will progress to $\mathrm{mPCa}$ when diagnosed., ${ }^{2,3}$ Conventional treatment of patients with $\mathrm{mPCa}$ is converted to chemotherapy with docetaxel when proceeding to castration-resistant prostate cancer (CRPC) after androgen deprivation therapy (ADT) based on androgen axis control. ${ }^{1,4}$ However, the treatment of $\mathrm{mPCa}$ has changed significantly in the past few years. Recently, hormone drugs with new indications-before and after chemotherapy-have been developed. $^{5}$ In addition, existing treatment options have been merged to broaden the scope of alternative therapies. The addition of ADT and 6-cycle docetaxel chemotherapy in patients with $\mathrm{M} 1 \mathrm{mPCa}$ has been reported to confer a survival advantage over treatment with ADT alone. ${ }^{6}$ However, despite these new drugs and methods, at approximately $30 \%$, the 5-year survival rate of patients with $\mathrm{mPCa}$ at a

This is an Open Access article distributed under the terms of the Creative Commons Attribution Non-Commercial License (http://creativecommons.org/licenses/by-nc/4.0/) which permits unrestricted non-commercial use, distribution, and reproduction in any medium, provided the original work is properly cited. 2020 (C) Copyright The Korean Urological Oncology Society and The Korean Prostate Society. All Rights Reserved. 
stage higher than M1a has not improved significantly. ${ }^{7}$ Local treatment (LT), such as radiation therapy (RT) and radical prostatectomy (RP), have been used only for palliative purposes and locoregional symptom relief. ${ }^{1,4}$ However, cytoreductive RP (CRP) for primary tumors in those with $\mathrm{mPCa}$ is not recommended due to the lack of evidence supporting its oncological benefits. Cytoreductive surgery for these primary tumors has proven to be beneficial in colorectal, breast, ovarian, and kidney cancers. ${ }^{8,9}$ Recent advances in surgical techniques and understanding suggest a potential role for CRP in $\mathrm{mPCa}$. In the present review, we examine the theoretical background of CRP, and the results of preclinical, retrospective case-control, population-based, and prospective studies.

\section{MATERIALS AND METHODS}

The purpose of this article is to review the theoretical background of and rationale for CRP, and the current knowledge base. The Scopus and PubMed databases were searched for studies investigating CRP published between January 2000 and October 2019. The retrieved articles were nonsystematically reviewed. Based on preclinical data, retrospective patient case studies, retrospective populationbased studies, and prospective studies. Articles related to the topic were searched using the keywords "cytoreductive" and "radical prostatectomy," "metastatic prostate cancer," "local therapy in metastatic prostate cancer," "local treatment in metastatic prostate cancer," "radical prostatectomy in metastatic prostate cancer," "cytoreductive prostatectomy," "cytoreductive radical prostatectomy," "cytoreductive surgery." The pubmed.gov and Scopus databases were searched, duplicates were removed, and titles and abstracts were reviewed. Studies investigating the survival benefits of CRP in node-positive patients were excluded, as were those addressing differences between robotic CRP and open CRP procedures. Finally, retrospective case studies with $<10$ patients were also excluded.

\section{Evidence Supporting the Benefit of Primary Tumor Control in Metastatic Disease}

There is no confirmed theory supporting the benefits of primary tumor therapy in metastatic disease. However, there are studies that support the hypothesis that treatment of pri- mary tumors is beneficial in the treatment of metastatic disease. ${ }^{10-13}$ Kaplan et al. ${ }^{13}$ proposed a premetastatic niche hypothesis, in which metastasis is caused by circulating tumor cells disseminated from primary tumors. When progenitor cell proliferation is activated by tumor-specific chemokines, the premetastatic niche of bone marrow is activated. Activated premetastatic niche helps the precursor cells move into the circulatory system. ${ }^{13}$ Progenitor cells move to other organs through the blood to cause the microenvironmental changes necessary for metastasis. ${ }^{13}$ The cancer self-seeding model is the theory that primary tumors act as a source of metastatic cells. ${ }^{10}$ Circulating tumor cells derived from primary tumors mediate metastasis and accelerate tumor growth by promoting stromal recruitment and angiogenesis through seed-derived factors at metastasized sites. ${ }^{10}$ It also releases additional metastatic cells at the site of metastasis, which return to primary tumors and grow. ${ }^{10}$ Genetic sequencing studies of metastatic spread patterns in $\mathrm{mPCa}$ have reported a characteristic pattern for many metastases from primary tumors to primary tumors, although there is also spread from metastasis to metastasis. ${ }^{11,12}$ Based on these findings, therefore, controlling primary tumors can eliminate one of the main causes of metastasis. ${ }^{11,12}$ The exact mechanism of the effects of CRP for primary tumor control on metastatic disease remains unclear; however, studies investigating various carcinomas have demonstrated that primary tumor control has advantages for overall survival (OS). ${ }^{8}$ In particular, CRP has a known survival benefit in colorectal, ovarian, breast, and kidney cancers. ${ }^{8}$

\section{Preclinical Studies of CRP}

There have been preclinical, experimental animal studies investigating the clinical utility of $\mathrm{CRP}$ in $\mathrm{mPCa}{ }^{14,15}$ Cifuentes et al. ${ }^{15}$ studied the metastatic dynamics of $\mathrm{mPCa}$ and the effects of CRP in animal models of mPCa by injecting prostate cancer cells into immunocompromised mice. The development and growth of primary tumors were confirmed to contribute to the growth and understanding of metastasis. ${ }^{15}$ Other studies have investigated the effects of reducing cell numbers at the metastasis stage. ${ }^{14}$ CRP was performed on orthotopic mice with $\mathrm{mPCa}$, and less metastasis was observed in the operated mice. ${ }^{14}$ These small studies provide preclinical evidence supporting the benefits of eliminating primary lesions in $\mathrm{mPCa}{ }^{14,15}$ 


\section{Benefit of CRP on Local Symptoms in mPCa}

Traditional CRP in patients with $\mathrm{mPCa}$ has played a palliative role in controlling locoregional progression. Approximately $80 \%$ of individuals with $\mathrm{mPCa}$ are likely to experience locoregional complications as the disease progresses. ${ }^{16}$ Moreover, approximately $30 \%$ of urinary tract complications, such as bladder outlet obstruction, are expected to require surgical intervention. ${ }^{17-19}$ In a retrospective study involving patients with CPRC, Steinberg et al. $^{20}$ reported that individuals who had previously received LT, such as RP and RT, demonstrated lower rates of local complications requiring surgical intervention than those who did not. In particular, patients who underwent RP exhibited the lowest complication rate. CRP has the benefit of lowering local complications in patients with $\mathrm{mPCa}$. Heidenreich et al. ${ }^{21}$ reported that patients treated with CRP had a 30\% lower rate of local complications than those treated with ADT alone. Won et al. ${ }^{19}$ reported that patients treated with RP and ADT, and RT and ADT, demonstrated a lower rate of local complications (by approximately 34\%) compared to those treated with ADT alone. Grimm et al. ${ }^{22}$ reported that patients treated with RP, RP, and ADR exhibited a lower rate of local complications $(34 \%-38 \%)$ than those treated with ADT in a study of node-positive patients. LTs, such as RT and RP, can reduce symptoms by inhibiting locoregional progression by approximately $20 \%-50 \%$ in patients with $\mathrm{mPCa}{ }^{1}$ Leibovici et al. ${ }^{23}$ used palliative RP and cystoprostatectomy with urinary diversion to alleviate symptoms in $78 \%$ of patients with advanced systemic refractory $\mathrm{mPCa}$. These findings suggest that CRP may help reduce local complications caused by locoregional progression and improve the quality of life of patients with mPCa.

\section{Oncological Outcomes From Population-Based Studies Investigating RP in mPCa}

Several population-based studies have demonstrated that CRP can benefit survival in patients with $\mathrm{mPCa}$ (Table 1). ${ }^{24-29}$ In a study using the Surveillance Epidemiology and End Results database, Culp et al. ${ }^{30}$ compared 245 patients who underwent CRP and 129 who underwent brachytherapy among 8185 patients with M1 PCa compared with those who did not receive LT.30 OS rates were $22.5 \%, 67.5 \%$, and $52.6 \%$ in those who underwent CRP, brachytherapy, and those without LT, respectively. In the CRP group, OS was highest in those who also underwent brachytherapy,

Table 1. Population based studies evaluating the role of radical prostatectomy in metastatic prostate cancer

\begin{tabular}{|c|c|c|c|c|}
\hline Study & $\begin{array}{l}\text { No. of } \\
\text { patients }\end{array}$ & Stage & Intervention group & Results \\
\hline Culp et al. $^{30}$ & 8,185 & M1a-c & CRP, BT, Non-LT & $\begin{array}{l}\text { 5-Year OS: } 67.4 \%, 52.6 \%, 22.5 \% \\
\text { 5-Year CSS: } 75.8 \%, 61.3 \%, 48.7 \%\end{array}$ \\
\hline Antwi and Everson ${ }^{31}$ & 7,858 & M1a-c & CRP, BT, Non-LT & Median survival time: $29,31,17$ months \\
\hline Satkunasivam et al. ${ }^{29}$ & 4,069 & M1a-c & CRP, CRT, IMRT, Non-LT & $\begin{array}{l}\text { 3-Year OS: } 73 \%, 37 \%, 72 \%, 34 \% \\
\text { 3-Year CSS: } 79 \%, 49 \%, 82 \%, 46 \%\end{array}$ \\
\hline Fossati et al. $^{24}$ & 8,197 & M1a-c & LT, Non-LT & $\begin{array}{l}\text { 3-Year DSS (PPCSM 30\%): 82\%, 65\% } \\
\text { 3-Year DSS (PPCSM 40\%): } 78 \%, 58 \% \\
\text { 3-Year DSS (PPCSM 50\%): } 48 \%, 52 \%\end{array}$ \\
\hline Leyh-Bannurah et al. ${ }^{26}$ & 13,692 & M1a-c & LT (RP, RT), Non-LT & $\begin{array}{l}\text { CSM }(\mathrm{LT}<\mathrm{Non}-\mathrm{LT}): \text { HR } 0.40,95 \% \text { CI } 0.32-0.50 \\
\mathrm{CSM}(\mathrm{RP}<\mathrm{RT}): \text { HR } 0.59,95 \% \text { CI } 0.35-0.99\end{array}$ \\
\hline Parikh et al. ${ }^{28}$ & 6,051 & M1a-c & LT (CRP, CRT, IMRT), Non-LT & 5-Year OS: $45.7 \%, 17.1 \%$ \\
\hline Löppenbergs et al. ${ }^{27}$ & 15,501 & M1a-c & LT (RP, RT), Non-LT & $\begin{array}{l}\text { 3-Year OMFS: } 69 \%, 54 \% \\
\text { 3-Year OMFS }(\mathrm{OM} \text { risk } \leq 20 \%): 15.7 \% \\
\text { 3-Year OMFS }(\mathrm{OM} \text { risk } \geq 70 \%): 0 \%\end{array}$ \\
\hline Gratzke et al. ${ }^{25}$ & 1,538 & M1 & CRP, Non-LT & 5-Year OS: $21 \%, 55 \%$ \\
\hline
\end{tabular}

CRP: cytoreductive radical prostatectomy, BT: brachytherapy, LT: local therapy, OS: overall survival, CSS: cancer specific survival, IMRT: intensity-modulated radiation therapy, DSS: disease specific survival, PPCSM: predicted prostate cancer-specific mortality, CSM: cancer specific mortality, HR: hazard ratio, CI: confidence interval, CRT: conformal radiation therapy, RP: radical prostatectomy, RT: radiation therapy, OMFS: overall mortalityfree survival, OM: overall mortality. 
compared with the non-LT group. ${ }^{30}$ Antwi and Everson ${ }^{31}$ reported reduced overall mortality (hazard ratio [HR], 0.27; 95\% confidence interval $[\mathrm{CI}], 0.20-0.38]$ ) and cancer-specific mortality (CSM: HR, 0.28; 95\% CI, 0.20-0.39) in patients who underwent CRP compared to those who did not receive LT. Satkunasivam et al. ${ }^{29}$ compared $\mathrm{mPCa}$ patients who underwent CRP, intensity-modulated radiation therapy (IMRT), and conformal radiation therapy (CRT) and did not receive LT. Among the 4,069 patients with M1 prostate cancer, 47 who underwent CRP, 88 who underwent IMRT, 107 who received CRT, and those who did not receive LT were compared. ${ }^{29}$ Patients who underwent CRP (HR, 0.48; 95\% CI, 0.27-0.85) and IMRT (HR, 0.38; 95\% CI, 0.240.61) demonstrated significantly reduced CSM compared to those who did not undergo $\mathrm{LT}^{29}{ }^{29}$ Fossati et al. ${ }^{24}$ compared 8,197 patients with M1 mPCa with those who received LT, including CRP and brachytherapy, and those without LT. Multivariate Cox regression was used to calculate the 3-year CSM risk at diagnosis. ${ }^{24}$ According to CSM, the group treated with LT and the group not treated were compared. ${ }^{24}$ In patients with a predicted CSM $<40 \%$, patients who underwent LT demonstrated higher CSM-free survival than those who did not receive $\mathrm{LT}^{24}$ In the case of $>50 \%$ predicted CSM, LT demonstrated no survival benefit. ${ }^{24}$ LeyhBannurah et al. ${ }^{26}$ compared M1 mPCa patients with those who received local RP and RT, and those without LT. Of the 13,692 mPCa patients, 313 underwent RP and $161 \mathrm{RT}$. Patients who received LT (HR, 0.40; 95\% CI, 0.32-0.50) demonstrated significantly reduced CSM compared to those who did not receive $\mathrm{LT}^{26}$ In the LT group, RP (HR, 0.59; 95\% CI, 0.35-0.99) resulted in a lower CSM than $\mathrm{RT}^{26}$

In a study using the National Cancer Database, Parikh et al. $^{28}$ compared mPCa patients who underwent CRP, IMRT, and CRT and did not receive LT. The 5-year survival rates were $45.7 \%$ versus $17.1 \%$ in the patients who were treated and were not treated LT. In multivariate analysis, CRP (HR, $0.51 ; 95 \% \mathrm{CI}, 0.45-0.59 ; \mathrm{p}<0.01)$ and IMRT (HR, 0.47; 95\% CI, 0.31-0.72; $<<0.01)$ were significantly associated with better OS, respectively. ${ }^{28}$ Löppenberg et al. ${ }^{27}$ analyzed $15,501 \mathrm{mPCa}$ patients and compared the groups with and without LT, such as RP and RT. A total of 1,470 patients (9.5\%) underwent LT, and the 3-year OS for LT and non-LT was $69 \%$ versus $^{12} 54 \%$, respectively. ${ }^{26}$ There was a survival benefit for LT in the group with low predicted overall mortality risk and no LT survival benefit in the group with $\geq 70 \%$ of the estimated overall mortality risk. ${ }^{27}$ In a study using the Munich Cancer Registry, Gratzke et al. $^{25}$ compared 74 patients who underwent CRP of 1,538 mPCa patients to those who did not receive $\mathrm{LT}^{25}$ The 5 -year survival rates were $55 \%$ versus $21 \%$ in the CRP and non-LT groups, respectively.

\section{Oncological Outcomes in Retrospective Case Studies Investigating RP in $\mathbf{m P C a}$}

Several retrospective studies have demonstrated that CRP can benefit survival in patients in $\mathrm{mPCa}$ (Table 2). ${ }^{21,32,33}$ Heidenreich et al. ${ }^{21}$ compared oligometastatic prostate cancer in 23 patients who underwent CRP after neoadjuvant ADT, and 38 patients who underwent ADT alone. The CRP group included patients with prostate-specific antigen (PSA) levels $<1.0 \mathrm{ng} / \mathrm{mL}$ after neoadjuvant ADT for 6 months. In the CRP group, 13 patients had a positive margin and were node-positive, and 5 experienced biochemical recurrence $(21.7 \%){ }^{21}$ Time to CRPC was 40 months versus 29 months

Table 2. Retrospective case studies evaluating the role of radical prostatectomy in metastatic prostate cancer

\begin{tabular}{|c|c|c|c|c|}
\hline Study & $\begin{array}{l}\text { No. of } \\
\text { patients }\end{array}$ & Stage & Intervention group & Results \\
\hline $\begin{array}{l}\text { Heidenreich } \\
\text { et al. }\end{array}$ & 61 & M1b (Oligometastatic) & Neoadjuvant ADT+CRP, ADT & $\begin{array}{l}\text { OS: } 91.3 \%, 78.9 \% \\
\text { DSS: } 95.6 \%, 84.2 \%\end{array}$ \\
\hline $\begin{array}{l}\text { Heidenreich } \\
\text { et al. }{ }^{32}\end{array}$ & 113 & M1b (Oligometastatic) & CRP & $\begin{array}{l}\text { 3-Year OS: } 87.6 \%, 5 \text {-year OS: } 79.6 \% \\
\text { Clinical RFS: } 72.3 \text { months }\end{array}$ \\
\hline $\begin{array}{l}\text { Gandaglia } \\
\text { et } \text { al. }^{33}\end{array}$ & 11 & M1b (Oligometastatic) & CRP & $\begin{array}{l}\text { 7-Year clinical PFS: } 45 \% \\
\text { CSS: } 82 \%\end{array}$ \\
\hline
\end{tabular}

ADT: androgen deprivation therapy, CRP: cytoreductive radical prostatectomy, CSS: cancer specific survival, OS: overall survival, DSS: disease specific survival, RFS: relapse-free survival. 
in the CRP and ADT groups, respectively, and progressionfree survival was 38.6 months versus 26.5 months. Cancerspecific survival (CSS) was $95.6 \%$ versus $84.2 \%$, and OS was $91.3 \%$ versus $78.9 \%{ }^{21}$ Heidenreich et al. ${ }^{32}$ compared the oligometastatic PCa of 113 patients with CRP., and $36.8 \%$ of patients had a positive margin and $61.6 \%$ of patients were node-positive. ${ }^{32}$ The 3 -year OS of CRP patients was $87.6 \%$ and the 5 -year OS was $79.6 \%$. Clinical relapsefree survival was 72.3 months. ${ }^{32}$ Gandaglia et al. ${ }^{33}$ compared oligometastatic prostate cancer in 11 patients who underwent CRP. Eight patients had a positive margin and 10 were node-positive. The 7-year clinical progression-free survival and CSS were $45 \%$ and $82 \%$, respectively. ${ }^{33}$

\section{Oncological Outcomes in Prospective Case Studies Investigating RP in $\mathbf{m P C a}$}

Steuber et al. ${ }^{34}$ used prospective data to compare 43 patients with oligometastatic prostate cancer and 40 who underwent ADT. There was no significant difference in OS and castration resistant-free survival between the 2 groups. However, in the case of local complications, the CRP group and ADT group had a significant decrease in the CRP group (7.0\% vs. 35\%). ${ }^{34}$ Preliminary results of the Local Treatment of Metastatic Prostate Cancer (LoMP) trial have been published. ${ }^{35}$ The LoMP trial was conducted among patients with $\mathrm{mPCa}$ who underwent $\mathrm{CRP} .^{35}$ Patients with $\mathrm{mPCa}$ who showed no symptoms associated with metastatic lesions, had a resectable tumor, and a condition suitable for surgery

Table 3. Studies evaluating the role of the metastasis direct therapy in oligometastatic PCa patients

\begin{tabular}{|c|c|c|c|c|c|}
\hline Study & Study type & $\begin{array}{l}\text { No. of } \\
\text { patients }\end{array}$ & Stage & Intervention group & Results \\
\hline $\begin{array}{l}\text { Palma } \\
\text { et al. }\end{array}$ & $\begin{array}{l}\text { Randomized } \\
\text { phase II trial }\end{array}$ & 99 & Oligorecurrent CRPC & MDT, SOC & $\begin{array}{l}\text { Median OS: } 41,28 \text { months } \\
\text { Median PFS: } 12,6 \text { months }\end{array}$ \\
\hline $\begin{array}{l}\text { Ost } \\
\text { et } \text { al. }^{39}\end{array}$ & $\begin{array}{l}\text { Randomized } \\
\text { phase II trial }\end{array}$ & 62 & Oligorecurrent HSPC & $\begin{array}{l}\text { Surgery or } \\
\text { SBRT, Surveilance }\end{array}$ & Median AFS: 21, 13 months \\
\hline $\begin{array}{l}\text { Tran } \\
\text { et al. }\end{array}$ & $\begin{array}{l}\text { Randomized } \\
\text { phase II trial }\end{array}$ & 36 & Oligorecurrent HSPC & $\begin{array}{l}\text { SBRT, } \\
\text { Surveilance }\end{array}$ & 6-Month PFS: $67 \%, 33 \%$ \\
\hline $\begin{array}{l}\text { Siva } \\
\text { et al. }{ }^{41}\end{array}$ & Prospective & 50 & Oligorecurrent $\mathrm{PCa}$ & SBRT & 1-Year PFS: $58 \%$, 2-year PFS: $39 \%$ \\
\hline $\begin{array}{r}\text { Bowden } \\
\text { et al. }{ }^{42}\end{array}$ & Prospective & 199 & Oligorecurrent $\mathrm{PCa}$ & SBRT & 2-Year FFTE: $51.7 \%$ \\
\hline $\begin{array}{l}\text { Kneebone } \\
\text { et } \text { al. }^{43}\end{array}$ & Prospective & 57 & Oligorecurrent HSPC & SBRT & $\begin{array}{l}\text { Median bDFS: } 11 \text { months, 2-year AFS: } \\
48 \%\end{array}$ \\
\hline $\begin{array}{l}\text { Deek } \\
\text { et al. }\end{array}$ & Retrospective & 156 & Oligorecurrent $\mathrm{PCa}$ & MDT & $\begin{array}{l}\text { 1-Year bPFS: } 57 \% \text {, 2-year bPFS: } 40 \% \\
\text { Median AFS: } 27.8 \text { months }\end{array}$ \\
\hline $\begin{array}{l}\text { Muldermans } \\
\text { et al. }\end{array}$ & Retrospective & 66 & Oligorecurrent $\mathrm{PCa}$ & MDT & $\begin{array}{l}\text { 2-Year bPFS: } 54 \% \\
\text { 2-Year PFS: } 45 \% \\
\text { 2-Year OS: } 83 \%\end{array}$ \\
\hline $\begin{array}{l}\text { Ingrosso } \\
\text { et al. }{ }^{46}\end{array}$ & Retrospective & 40 & Oligorecurrent HSPC & MDT & 2-Year bPFS: $44 \%$ \\
\hline $\begin{array}{l}\text { Moyer } \\
\text { et } \text { al. }^{47}\end{array}$ & Retrospective & 66 & Oligorecurrent $\mathrm{PCa}$ & MDT & $\begin{array}{l}\text { 1-Year bPFS: } 69 \% \text {, 1-year PFS: } 69 \% \\
\text { 1-Year AFS: } 78 \%\end{array}$ \\
\hline $\begin{array}{l}\text { Decastecker } \\
\text { et } \text { al. }^{48}\end{array}$ & Retrospective & 50 & Oligorecurrent HSPC & MDT & $\begin{array}{l}\text { Medain AFS: } 25 \text { months } \\
\text { 1-Year AFS: } 82 \% \text {, 2-year AFS } 60 \%\end{array}$ \\
\hline $\begin{array}{l}\text { Berkovic } \\
\text { et al. }{ }^{49}\end{array}$ & Retrospective & 24 & Oligorecurrent HSPC & MDT & $\begin{array}{l}\text { Medain AFS: } 38 \text { months } \\
\text { 1-Year AFS: } 82 \% \text {, 2-year AFS 54\% }\end{array}$ \\
\hline
\end{tabular}

PCa: prostate cancer, CRPC: castration-resistant prostate cancer, MDT: metastasis direct therapy, SOC: standard of care, OS: overall survival, PFS: progression free survival, HSPC: hormone sensitive prostate cancer, SBRT: stereotactic body radiotherapy, AFS: androgen deprivation therapy free survival, FFTE: freedom from treatment escalation, bDFS: biochemical disease-free survival, bPFS: biochemical progression free survival. 
were included. ${ }^{35}$ The standard care and CRP groups were compared. ${ }^{35}$ Two-year OS and CSS in the CRP group and the standard care group were $100 \%$ versus $61 \%$, and $100 \%$ versus $55 \%$, respectively. ${ }^{35}$ The CRP group demonstrated no progression to CRPC, $23.5 \%$ exhibited a PSA response, $44.8 \%$ had CRPC, and $24.1 \%$ died in the standard care group. ${ }^{35}$

\section{Metastasis Direct Therapy in $\mathrm{mPCa}$}

In addition to local therapy of primary tumors, several studies have reported that reduced treatment of metastatic burden is associated with survival benefit. ${ }^{36-49}$ It is based on Halstead and Hellman's hypothesis that cancer ranges from locally defined too broadly metastatic. ${ }^{36,37}$ According to these 2 hypotheses, the metastasis state is divided into an oligometastatic state, which is considered to be an early sign of systemic macrometastasis with a limited number of metastases less than 5, and a high-volume metastatic state with 5 or more metastases. ${ }^{36,37}$ Metastasis direct therapy (MDT) in oligometastatic states, which are metastatic in this early short-term, helps to prolong survival by reducing the burden of metastatic lesions. Table 3 shows the results of studies related to the treatment of metastatic lesions in these oligometastatic PCa patients. ${ }^{38-49}$ Several RCT studies have shown that MDT, such as surgery or stereotactic body radiotherapy (SBRT), has an advantage over survival in patients with Oligorecurrent PCa. Palma et al. ${ }^{38}$ reported median OS and PFS improvement in the MDT group compared to the standard of care group. Ost et al. ${ }^{39}$ reported that median ADT free survival was improved in Surgery or SBRT group compared with surveillance group. Tran et al. ${ }^{40}$ reported a 6-month PFS improvement in the SBRT group compared to the surveillance group. Several prospective and retrospective studies report median ADT free survival of approximately 21 to 38 months and 2-year PFS of approximately $39 \%$ to $54 \%$ in the MDT group. ${ }^{41-49}$

\section{Feasibility of Cytoreductive Radical Prostatectomy}

Retrospective studies have been conducted on the safety and feasibility of CRP. ${ }^{21,33,50}$ Heidenreich et al. ${ }^{21}$ compared patients with mPCa treated with RP and pelvic lymph node dissection who had low-volume skeletal metastasis and those treated with ADT without local therapy. The ClavienDindo classification of the complications in the CRP group was as follows: grade IV-V, $0 \%$; grade III, $13 \%$; grade II, $8 \%$; and grade I, 17\%.21 The ADT group had complications that required surgery or intervention, with approximately $30 \%$ local progression, and the CRP group had no complications due to local progression. ${ }^{21}$

Gandaglia et al. $^{33}$ reported a 5-year follow-up of CRPtreated patients among those with oligometastatic mPCa. In their study, only approximately $18 \%$ of patients reported complications of Clavien grade 3 or higher after CRP. ${ }^{33}$ In a multicenter study of CRP for distant $\mathrm{mPCa}$, post-CRP complications occurred in $21 \%$ of the patients and ClavienDindo classification grade III or higher complications occurred in $8 \%{ }^{50}$ The functional result after surgery was $82 \%$ in the patients who used less than one pad a year after surgery and $64 \%$ in those who were pad-free. ${ }^{50}$ This was not significantly different from the post-RP outcome in patients with high-risk prostate cancer. Even patients with prostate cancer with distant metastasis may be similar to those with locally advanced prostate cancer if the disease is limited to the prostate area. For this reason, functional outcomes and complication rates may be similar, and in the case of $\mathrm{mPCa}$ without metastasis to peripheral organs, CRP is feasible. In terms of stability and functionality, CRP is unlikely to differ significantly from high-risk prostate cancer surgery.

\section{CONCLUSIONS}

CRP for $\mathrm{mPCa}$ has been reported to confer benefits for the treatment and prevention of local symptoms and improvement of survival outcomes through the removal of primary tumors, the management of neo-metastatic disease, the control of tumor burden. However, the rationale for CRP is based mainly on preclinical and retrospective studies, without large-scale prospective and randomized controlled trials. Further research investigating the role and timing of CRP in patients with mPCa is needed, as well as studies screening populations most suitable for the procedure.

\section{CONFLICT OF INTEREST}

The authors claim no conflicts of interest. 


\section{REFERENCES}

1. Metcalfe MJ, Smaldone MC, Lin DW, Aparicio AM, Chapin BF. Role of radical prostatectomy in metastatic prostate cancer: a review. Urol Oncol 2017;35:125-34.

2. James ND, Spears MR, Clarke NW, Dearnaley DP, De Bono JS, Gale J, et al. Survival with newly diagnosed metastatic prostate cancer in the "docetaxel era": data from 917 patients in the control arm of the STAMPEDE Trial (MRC PR08, CRUK/06/019). Eur Urol 2015;67:1028-38.

3. Norum J, Nieder C. Treatments for metastatic prostate cancer (mPC): a review of costing evidence. Pharmacoeconomics 2017;35:1223-36.

4. Cornford P, Bellmunt J, Bolla M, Briers E, De Santis M, Gross T, et al. EAU-ESTRO-SIOG guidelines on prostate cancer. Part II: treatment of relapsing, metastatic, and castration-resistant prostate cancer. Eur Urol 2017;71:630-42.

5. Thiery-Vuillemin A, Poulsen MH, Lagneau E, Ploussard G, Birtle A, Dourthe LM, et al. Impact of abiraterone acetate plus prednisone or enzalutamide on patient-reported outcomes in patients with metastatic castration-resistant prostate cancer: final 12-mo analysis from the observational AQUARiUS Study. Eur Urol 2020;77:380-7.

6. James ND, Sydes MR, Clarke NW, Mason MD, Dearnaley DP, Spears MR, et al. Addition of docetaxel, zoledronic acid, or both to first-line long-term hormone therapy in prostate cancer (STAMPEDE): survival results from an adaptive, multiarm, multistage, platform randomised controlled trial. Lancet 2016;387:1163-77.

7. All Races, Males by SEER Summary Stage (2000) SEER 18 2010-2016 [Internet]. Bethesda (MD): National Cancer Institute; [cited 2020 Aug 20]. Available from: https://seer. cancer.gov/statfacts/html/prost.html.

8. Cole BF, Gelber RD, Gelber S, Coates AS, Goldhirsch A. Polychemotherapy for early breast cancer: an overview of the randomised clinical trials with quality-adjusted survival analysis. Lancet 2001;358:277-86.

9. Cotte E, Passot G, Mohamed F, Vaudoyer D, Gilly FN, Glehen O. Management of peritoneal carcinomatosis from colorectal cancer: current state of practice. Cancer J 2009; 15:243-8.

10. Comen E, Norton L, Massagué J. Clinical implications of cancer self-seeding. Nat Rev Clin Oncol 2011;8:369-77.

11. Gundem G, Van Loo P, Kremeyer B, Alexandrov LB, Tubio JMC, Papaemmanuil E, et al. The evolutionary history of lethal metastatic prostate cancer. Nature 2015;520: 353-7.

12. Hong MK, Macintyre G, Wedge DC, Van Loo P, Patel K, Lunke $\mathrm{S}$, et al. Tracking the origins and drivers of subclonal metastatic expansion in prostate cancer. Nat Commun
2015;6:6605.

13. Kaplan RN, Psaila B, Lyden D. Bone marrow cells in the 'pre-metastatic niche': within bone and beyond. Cancer Metastasis Rev 2006;25:521-9.

14. Cifuentes FF, Valenzuela RH, Contreras HR, Castellón EA. Surgical cytoreduction of the primary tumor reduces metastatic progression in a mouse model of prostate cancer. Oncol Rep 2015;34:2837-44.

15. Cifuentes FF, Valenzuela RH, Contreras HR, Castellón EA. Development of an orthotopic model of human metastatic prostate cancer in the NOD-SCID $\gamma$ mouse (Mus musculus) anterior prostate. Oncol Lett 2015;10:2142-8.

16. Patrikidou A, Brureau L, Casenave J, Albiges L, Di Palma $\mathrm{M}$, Patard JJ, et al. Locoregional symptoms in patients with de novo metastatic prostate cancer: morbidity, management, and disease outcome. Urol Oncol 2015;33:202. e9-17.

17. Alemayehu B, Buysman E, Parry D, Becker L, Nathan F. Economic burden and healthcare utilization associated with castration-resistant prostate cancer in a commercial and Medicare Advantage US patient population. J Med Econ 2010;13:351-61.

18. Aus G, Hugosson J, Norlén L. Need for hospital care and palliative treatment for prostate cancer treated with noncurative intent. J Urol 1995;154(2 Pt 1):466-9.

19. Won AC, Gurney H, Marx G, De Souza P, Patel MI. Primary treatment of the prostate improves local palliation in men who ultimately develop castrate-resistant prostate cancer. BJU Int 2013;112:E250-5.

20. Steinberg GD, Epstein JI, Piantadosi S, Walsh PC. Management of stage D1 adenocarcinoma of the prostate: the Johns Hopkins experience 1974 to 1987. J Urol 1990; 144:1425-32.

21. Heidenreich A, Pfister D, Porres D. Cytoreductive radical prostatectomy in patients with prostate cancer and low volume skeletal metastases: results of a feasibility and casecontrol study. J Urol 2015;193:832-8.

22. Grimm MO, Kamphausen S, Hugenschmidt H, StephanOdenthal M, Ackermann R, Vögeli TA. Clinical outcome of patients with lymph node positive prostate cancer after radical prostatectomy versus androgen deprivation. Eur Urol 2002;41:628-34.

23. Leibovici D, Kamat AM, Pettaway CA, Pagliaro L, Rosser CJ, Logothetis C, et al. Cystoprostatectomy for effective palliation of symptomatic bladder invasion by prostate cancer. J Urol 2005;174:2186-90.

24. Fossati N, Trinh QD, Sammon J, Sood A, Larcher A, Sun $\mathrm{M}$, et al. Identifying optimal candidates for local treatment of the primary tumor among patients diagnosed with metastatic prostate cancer: a SEER-based study. Eur Urol 2015; 67:3-6.

25. Gratzke C, Engel J, Stief CG. Role of radical prostatec- 
tomy in metastatic prostate cancer: data from the Munich Cancer Registry. Eur Urol 2014;66:602-3.

26. Leyh-Bannurah SR, Gazdovich S, Budäus L, Zaffuto E, Briganti A, Abdollah F, et al. Local therapy improves survival in metastatic prostate cancer. Eur Urol 2017;72:11824.

27. Löppenberg B, Dalela D, Karabon P, Sood A, Sammon JD, Meyer CP, et al. The impact of local treatment on overall survival in patients with metastatic prostate cancer on diagnosis: a national cancer data base analysis. Eur Urol 2017;72:14-9.

28. Parikh RR, Byun J, Goyal S, Kim IY. Local therapy improves overall survival in patients with newly diagnosed metastatic prostate cancer. Prostate 2017;77:559-72.

29. Satkunasivam R, Kim AE, Desai M, Nguyen MM, Quinn DI, Ballas L, et al. Radical prostatectomy or external beam radiation therapy vs no local therapy for survival benefit in metastatic prostate cancer: a SEER-medicare analysis. J Urol 2015;194:378-85.

30. Culp SH, Schellhammer PF, Williams MB. Might men diagnosed with metastatic prostate cancer benefit from definitive treatment of the primary tumor? A SEER-based study. Eur Urol 2014;65:1058-66.

31. Antwi S, Everson TM. Prognostic impact of definitive local therapy of the primary tumor in men with metastatic prostate cancer at diagnosis: a population-based, propensity score analysis. Cancer Epidemiol 2014;38:435-41.

32. Heidenreich A, Fossati N, Pfister D, Suardi N, Montorsi $\mathrm{F}$, Shariat $\mathrm{S}$, et al. Cytoreductive radical prostatectomy in men with prostate cancer and skeletal metastases. Eur Urol Oncol 2018;1:46-53.

33. Gandaglia G, Fossati N, Stabile A, Bandini M, Rigatti P, Montorsi F, et al. Radical prostatectomy in men with oligometastatic prostate cancer: results of a single-institution series with long-term follow-up. Eur Urol 2017;72:289-92.

34. Steuber T, Berg KD, Røder MA, Brasso K, Iversen P, Huland $\mathrm{H}$, et al. Does Cytoreductive prostatectomy really have an impact on prognosis in prostate cancer patients with low-volume bone metastasis? Results from a prospective case-control study. Eur Urol Focus 2017;3:646-9.

35. Poelaert F, Verbaeys C, Rappe B, Kimpe B, Billiet I, Plancke $\mathrm{H}$, et al. Cytoreductive prostatectomy for metastatic prostate cancer: first lessons learned from the multicentric prospective local treatment of metastatic prostate cancer (LoMP) trial. Urology 2017;106:146-52.

36. Hellman S, Weichselbaum RR. Oligometastases. J Clin Oncol 1995;13:8-10.

37. Tosoian JJ, Gorin MA, Ross AE, Pienta KJ, Tran PT, Schaeffer EM. Oligometastatic prostate cancer: definitions, clinical outcomes, and treatment considerations. Nat Rev Urol 2017;14:15-25.

38. Palma DA, Olson R, Harrow S, Gaede S, Louie AV,
Haasbeek C, et al. Stereotactic ablative radiotherapy versus standard of care palliative treatment in patients with oligometastatic cancers (SABR-COMET): a randomised, phase 2, open-label trial. Lancet 2019;393:2051-8.

39. Ost P, Reynders D, Decaestecker K, Fonteyne V, Lumen N, De Bruycker A, et al. Surveillance or metastasis-directed therapy for oligometastatic prostate cancer recurrence: a prospective, randomized, multicenter phase II trial. J Clin Oncol 2018;36:446-53.

40. Tran P, Radwan N, Phillips R, Ross A, Rowe S, Gorin M, et al. OC-0505: interim results of a randomized trial of observation versus SABR for oligometastatic prostate cancer. Radiother Oncol 2018;127:S261.

41. Siva S, Bressel M, Murphy DG, Shaw M, Chander S, Violet J, et al. stereotactic abative body radiotherapy (SABR) for oligometastatic prostate cancer: a prospective clinical trial. Eur Urol 2018;74:455-62.

42. Bowden P, See AW, Frydenberg M, Haxhimolla H, Costello AJ, Moon D, et al. Fractionated stereotactic body radiotherapy for up to five prostate cancer oligometastases: Interim outcomes of a prospective clinical trial. Int $\mathrm{J}$ Cancer 2020;146:161-8.

43. Kneebone A, Hruby G, Ainsworth H, Byrne K, Brown C, Guo L, et al. Stereotactic body radiotherapy for oligometastatic prostate cancer detected via prostate-specific membrane antigen positron emission tomography. Eur Urol Oncol 2018;1:531-7.

44. Deek MP, Yu C, Phillips R, Song DY, Deville C, Greco $\mathrm{S}$, et al. Radiation therapy in the definitive management of oligometastatic prostate cancer: the johns hopkins experience. Int J Radiat Oncol Biol Phys 2019;105:948-56.

45. Muldermans JL, Romak LB, Kwon ED, Park SS, Olivier KR. Stereotactic body radiation therapy for oligometastatic prostate cancer. Int J Radiat Oncol Biol Phys 2016;95:696702.

46. Ingrosso G, Trippa F, Maranzano E, Carosi A, Ponti E, Arcidiacono F, et al. Stereotactic body radiotherapy in oligometastatic prostate cancer patients with isolated lymph nodes involvement: a two-institution experience. World J Urol 2017;35:45-9.

47. Moyer CL, Phillips R, Deek MP, Radwan N, Ross AE, Antonarakis ES, et al. Stereotactic ablative radiation therapy for oligometastatic prostate cancer delays time-to-next systemic treatment. World J Urol 2019;37:2623-9.

48. Decaestecker K, De Meerleer G, Lambert B, Delrue L, Fonteyne V, Claeys T, et al. Repeated stereotactic body radiotherapy for oligometastatic prostate cancer recurrence. Radiat Oncol 2014;9:135.

49. Berkovic P, De Meerleer G, Delrue L, Lambert B, Fonteyne V, Lumen N, et al. Salvage stereotactic body radiotherapy for patients with limited prostate cancer metastases: deferring androgen deprivation therapy. Clin Geni- 
tourin Cancer 2013;11:27-32.

50. Sooriakumaran P, Karnes J, Stief C, Copsey B, Montorsi $\mathrm{F}$, Hammerer $\mathrm{P}$, et al. A multi-institutional analysis of per- ioperative outcomes in 106 men who underwent radical prostatectomy for distant metastatic prostate cancer at presentation. Eur Urol 2016;69:788-94. 